International Journal of English Language Studies (IJELS)

ISSN: 2707-7578

DOI: $10.32996 /$ ijels

Website: https://al-kindipublisher.com/index.php/ijels

\title{
Competence of Students in the Realm of Communication Process: A Descriptive Study
}

\author{
Judaline S. Comiso 8 (D) \\ SHS Faculty, Mandaue City Comprehensive National High School, Cebu, Philippines \\ $\triangle$ Corresponding Author: Judaline S. Comiso, E-mail: judaline.comiso001@deped.gov.ph
}

ARTICLE INFORMATION ABSTRACT

Received: July 08, 2021

Accepted: August 14, 2021

Volume: 3

Issue: 8

DOI: $10.32996 /$ ijels.2021.3.8.1

\section{KEYWORDS}

Communication process, competence of students, descriptive study
The study employed the descriptive method of research with the questionnaires as the gathering tools. This method was used to gather necessary information regarding the communication process implemented at the Mandaue City College in Mandaue City, Cebu. The research subjects of the study were the second-year college students of Bachelor of Elementary Education college students of Mandaue City College. This study utilized a researcher-made survey questionnaire as the main tool in gathering the necessary data. The indicators on the questionnaire were based on the theories and principles of communication process and understanding by Wiggins and McTighe. The researcher prepared a questionnaire for the college students and the other for the college teachers. The questionnaire determines the level of competence of the college students in the communication process. It also includes the methods and the instructional materials used by the teachers in enhancing the communication process. The validation was done by having this instrument answered by 10 or 10 percent of the final number of college student respondents. This validating group was not part of the final group who provided the answers to the questions asked. Moreover, in relation to the level of competence of the student and teacher respondents in the communication process, it is exemplified that the college students are better at explaining compared to interpreting and applying. It is also revealed that the college teachers utilize varied teaching methods and techniques to the students in tertiary education. Furthermore, the following recommendations are hereby suggested: (1) The proposals of this study are presented to the administration of Mandaue City College for implementation and application in actual classroom practice. (2) The college students' interpreting skills be strengthened through the teacher's employment of varied and engaging strategies to develop their ability to interpret critically. (3) Teachers should employ exercises that would develop their students' applying skills through written and oral exercises.

\section{Introduction}

College students in the Philippines are confronted with many challenges in school. As global competitiveness is prompted in the academe, they are expected to comply with the standards of the school or university where they are currently enrolled. Schools in the country are now espousing development education with the goal of equipping them to possess the skills needed in the world of work. The 21st-century skills are competencies that college students at Mandaue City College, Mandaue City, Cebu need to enhance to survive in the challenges of the information era. The linkages for twenty-first-century skills list three types: Learning competencies, Literacy competencies, and Life competencies. These competencies are so relevant for college students, though they are specifically relevant in the modern world of work. When most professionals held jobs in the world of work, the necessary skills understanding trade, observing directions, relating with others, execute the job relentlessly and being effective worker-fast, accurate, just and trustworthy. Schools are a challenge to instil these competencies, and college students badly need them.
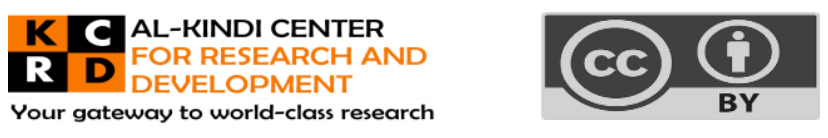

Published by Al-Kindi Center for Research and Development. Copyright (c) the author(s). This open access article is distributed under a Creative Commons Attribution (CC-BY) 4.0 license 
To keep relevant employment, college students also need to reflect deeply about concerns, address challenges creatively, build relationships teams, put across clearly in various media, learn innovative developments, and deal with enormous and varied knowledge. The fast innovations in the world require college students to be adaptable, take the initiative and lead when necessary, and produce something new and useful. Given of the above skills, it has been observed by human resource management officers observed that many college graduates do not possess these 21 st-century skills that are why they remain unemployed or underemployed. Therefore, schools are then tasked to produce globally competent graduates or at least can compete with their ASEAN computer parts. One of the efforts embark by language subject teachers is the so-called communication process.

Development education encompasses the college students' ability to decode or interpret the messages they get at home, in school or in the community. This ability in communication involves the college student's skill in explaining thorough accounts of the existing phenomenon. College students are also expected to interpret or tell meaningful stories or messages that provide multidimensional meanings, models, and analogies. Further, college students must also apply what is being decoded through effective use of what they assimilated in different contexts. Their perceptions about things are tested by their critical thinking and analytical skills, including decision making. Decoding also involves empathy among people, environment and culture. Further, college students in college need to enhance their self-knowledge. This is their awareness of their internal and external beings, their personal thinking styles, habits and uniqueness. This is the college students' ability to seek the value of each encounter with college students and their experiences.

Being a college professor handling language subjects and espousing innovative and college student-centered teaching, the researcher is embarking on this study to explore the phenomenon called development education through communication process at Mandaue City College. This study specifically assesses the college student's skills in the context of the communication process with the end in mind of recommending some proposals to institutionalize and improve the practice of enhancing the communication process in the teaching of language and social sciences.

\section{Theoretical Background}

This study is anchored on the various theories and perspectives in teaching-learning languages. These are the behaviourist view, postulated by Skinner, nativist by Noam Chomsky, particularly his language acquisition device, and Vygotsky's social interactionist view of language development.

College students learn in many and different ways. They love and enjoy engaging activities and competitions not just for rewards but because of the learning they get in the process. If applied in the actual classroom, these have been proven to be a motivation mechanism and an approach to learning the macro skills in the English language. The development of language skills among college students can be reinforced through practice and writing. This is done through various writing exercises which require the application of grammar rules. These macro skills in language among college students covered listening skills through giving and following instruction, mechanisms, reading skills through oral and silent reading and comprehension check, speaking skills through self-expression and conversation. Classroom activities are geared toward developing these skills for them to pass in the subjects today and become effective communicators in the future.

Proponents of behaviorism characteristics receptive English language to relationships that come out result from classical conditioning. For instance, every time the infant is offered a toy, the nanny names the object when she says, "Here is the toy." After continuous repetitions with the nanny presenting the task/thing and some words, the infant learns that the round and colored toy is a ball (Christie et al., 2007). In college classrooms, teachers conduct drills and review classes so that students can master the skills needed in preparation for higher and more complicated lessons.

Further, the nativist view of language and enhancement, with its highlights on nature, is at the other end of the continuum from the behaviorist undertaking. The Nativist view promotes that a individual's behavior and facilities are largely known in advance. Proponents of nativism believe that every college student has an inborn capability to learn a language. Its specialists were using utilizing information words. They would express those individuals are hardwired for a language. This innate capacity is called a language acquisition device (LAD). Noam Chomsky, a nativist, argues that the LAD allows college students to interpret phoneme models, word meanings, and the rules in communication using language. For example, when college students utilize past tenses, they often over-generalize certain words (Christie et al., 2007). One of the learning activities in college classrooms is vocabulary building to increase their level of comprehension. This vocabulary skill will make for effective writing.

Proponents of nativism also posit the innate language system facilities the college student's own attempts to converse, much the similar way as the computer's writing process the use of a number of software programs. Nativists posit that language acquisition varies in every learning exercise. A college student acquires the skill to relate through language even without support from significant others. They see the classroom's role in language acquisition as largely a function of activating the natural capabilities of the college student. Environment, these theorists believe, is the main strength that shapes a student's language 
capability (Christie et al., 2007). It is worthy to note that there are teachers who really structure their classrooms in such a way that it becomes conducive to learning and that students are motivated to learn because of the clean and beautiful classroom.

The social interactionists are skeptical of the nature versus nurture debate; rather, they recognize the influence of appearance and parental discipline. Theorists share with the proponents of behaviourism the belief that the environment plays a significant role in college students' language development. Likewise, along with nativist, social interactionists believe that some college student has an innate predisposition to acquire language competence. In addition, social interactionists highlight the college student's own in language acquisition and the making of meaning. The role of the parents and family background and experiences can never be underestimated. Therefore, it is relevant to each family, especially the parents, to actively participate in the student's learning through their moral and financial support.

The theory of Vygotsky shapes the social interactionist's view of language development. Vygotsky promoted that language developed in the realm of social interaction and language English utilization. As college students experience the different functions and forms of language, they internalize how their communication uses language to put the meaning across. Experiences in life shape the language the college student internalizes. At the same time, the college student is making a conscious effort to communicate to immerse and to express thoughts and feelings with the outside world. These efforts are simultaneous. Two forces, within and without the college student, work together to propel language learning. Cooperative learning and other approaches in language teaching are effective ways of enhancing language learning activities because human being in nature is sociable. Therefore, they learn better when they are with their friends and classmates.

The above theories and perspectives served as the framework in the development of the research problems and methodology as well as bases for analysis and interpretation of data.

\section{Related Literature and Related Studies}

Correspondence in the scholarly and genuine passes on the content from a sender to a collector in a far-reaching way. The pertinence of viable correspondence among individuals is unlimited in the scholastic enclosure, school, and individual life. In the connection of business and financial matters, viable correspondence generally covers the distinction in the middle of accomplishment and disappointment in a scholarly setting. Correspondence is getting to be in instructing learning procedure is basic to the fruitful and strategy in educating learning process. Each understudy needs to comprehend the essentials of successful correspondence in different settings and events.

At present, numerous scholarly organizations are extending aggregate quality learning. Powerful correspondence in the connection of scholastic exercises is the most imperative part of aggregate quality learning. The way how understudies see and correspond with each other in school about various issues is a noteworthy determinant of high scholastic accomplishment. While encountering poor relational abilities, it is demonstrated to debilitate efficiency and inevitably prompts poor scholastic execution among the learners.

The correspondence procedure is an apparatus in acknowledging yields and results, which can be accomplished through the methodology that has a typical significance between the sender and the collector. Understudies who take after the coral and composed dialect use will have the chance to end up more powerful in each part of their instruction. Powerful correspondence prompts their beneficial learning. There are four key components in the correspondence process. Those components incorporate encoding, medium of transmission, translating, and criticism. There are additionally two different variables all the while, and those two components are available as the sender and the collector. The typical correspondence process starts with the sender and closures with the collector.

The sender is the understudy, class, or school that starts the correspondence. This source is at first in charge of the fruitful transmittal of the message. The sender's year level, states of mind, learning, expertise, recognitions, society points of view in the message, the composed words, expressions and nonverbal inputs choice are fundamental in guaranteeing the collector translates the message as expected by the sender" (Burnett and Dollar, 2009). All correspondence starts with the sender. For this situation, this alludes to the understudies. The last association in the chain of the correspondence system is data. Consequent to getting a message, the beneficiary responds by one means and pictures that respond to the understudy sender. The sign may take a talked thought, a long mumble, a made substance, a grin, or some specific exercises. "Surely, even a nonattendance of response is in a manner of speaking, a kind of response" (Bovee \& Thill, 2002). Without information, the understudy sender cannot insist that the understudy authority has interpreted the message unequivocally.

Furthermore, school educators ought not to utilize addresses from references or some other material. Particularly not the Web. Ensure the inquiries set have not been examined in subtle elements in class. Obviously, the inquiries must be comparable; however, ensure that they are not the same. Instructors evaluate the undergrads on their artistic examination, not on their study abilities (Krystle, Hadley, et al., 2012). 
Villalta-Cerdas carried out a study that involves explaining skills in 2014 under the subject Chemistry. According to the study, the prevalent trend in chemistry instruction relies on what has been described as the classroom game. In this model, students take a passive role, and the instructor does all the explaining (thinking), and learning is trivialized to knowing the correct answers (memorizing) and being able to produce them when prompted (regurgitating). The generation of explanations is central to scientific and technological development. In the process of figuring out explanations, the generation of inferences relies on the application of skills associated with scientific behaviors

According to $\mathrm{Ma}$ (2103), the decoding procedure follows in an almost indiscernible instance, during which the interpreter processes the information stored in the "perceptual auditory storage" and extracts necessary information from both linguistic and non-linguistic codes. It is where the message is born. In this procedure, factors that will influence the quality of the interpretation include the source, particularly the speaker, the interpreter's linguistic competence and his background knowledge, which includes the knowledge of the world and knowledge of the subject under discussion.

The findings in the study of Villaroel (2011) indicate that English-speaking kindergarten through second-grade students enrolled in a Chinese program reported, in general, more positive attitudes toward both the Chinese and English languages in comparison with English-speaking students enrolled in schools with no world language program. This finding coincides somehow with findings made by researchers in studies of commonly taught languages without considering comparative schools. In this study, however, the effect of the school program in which the students were enrolled was further assessed by analyzing other factors that could also affect students' attitudes, the socioeconomic level of the school in which the students were enrolled.

However, another study conducted by Mwalyego (2014) revealed an ineffective utilization of available instruction materials by teachers and pupils during classroom instruction, whereby children are denied an opportunity to enjoy learning in the school context. Thus, it is important that teachers manage pre-primary units to utilize philosophy, which focuses on the young children's developmental needs. This can be attained if teachers are professionally committed, innovative and creative in designing and utilizing appropriate instructional materials for all learning activities.

Lastly, the participants in the study of Al Jabri (2008) all grant vocabulary high significance in their philosophy of teaching which is compatible with the importance of assigned vocabulary teaching in recent literature in the field of TESOL. However, they believe that their students' proficiency in vocabulary is far behind the required level in the grades they are teaching despite the efforts they claimed to exert in that area. They justified this lack of proficiency by citing the students' negative attitude towards the English language and the length of the curriculum. Through the analysis of the data collected with initial interviews and observations, it became obvious that there are some discrepancies between what the teachers said that they do and what they actually do in their EFL classes. The discrepancies appeared in the following areas: the teachers claimed that they provided context for new words, used the translation method as a last resort, and considered students' level of proficiency when choosing methods to teach abstract versus concrete words

\section{Research Problem}

This study assessed the level of competence in the communication process vis-à-vis dimension of tertiary instruction at Mandaue City College, Mandaue City Sports Complex A.S. Soriano Avenue, Mandaue City, Cebu during the school year 2014-2015 as the basis for the communication development plan.

Specifically, it sought to answer the following subproblems:

1. What is the level of competence of the college student respondents in the communication aspect along:

2.1 explaining;

2.2 interpreting; and

2.3 applying?

2. To what extent is the attainment of the aforementioned competencies through:

3.1 adequacy of instructional material; and

3.2 methods and techniques?

3. Based on the findings, what tertiary communication development plan can be proposed?

\section{Methodology}

The study employed the descriptive method of research with the questionnaires as the gathering tools. This method gathered necessary information regarding the communication process implemented at the Mandaue City College in Mandaue City, Cebu. The study subjects were the second-year college students of Bachelor of Elementary Education college students of Mandaue City College. A universal sampling of the population was used to determine all college students who have enrolled in the first semester of the school year 2015-2016. All the college teachers teaching English and Social Science subjects were the respondents of this study. 
It utilized a researcher-made survey questionnaire as the main tool in gathering the necessary data. The indicators on the questionnaire were based on the theories and principles of communication process and understanding by Wiggins and McTighe. The researcher prepared a questionnaire for the college students and the other for the college teachers. The questionnaire determines the level of competence of the college students in the communication process and the methods and the instructional materials used by the teachers in enhancing the communication process. The validation was done by having this instrument answered by 10 or 10 percent of the final number of college student respondents. This validating group was not part of the final group who provided the answers to the questions asked.

To obtain the data, a letter of request for permission to conduct the said study was prepared and was sent to the College Superintendent of Mandaue City College- A.S Soriano Ave. Mandaue City. The same letter already signed by the college superintendent was endorsed to the Dean of the College of Teacher Education. As soon as the concerned person in authority approved the letter, the researcher started her personal administration of the questionnaire to the identified respondents of the study. Informal interviews were likewise done to verify the authenticity of the responses made on their questionnaire. More so, a gathering of more data can be done. Moreover, the questionnaire was retrieved after the respondents have answered them completely. That questionnaire that was not answered during the researcher's personal administration were collected by the same after a period of one week.

\section{Results and Discussion}

Level of Competence of the Student Respondents in Communication Process

Table 1 presents the level of competence on the process of students as perceived by themselves and their teacher respondents in terms of explaining.

Table 1. Explaining

\begin{tabular}{|c|c|c|c|c|}
\hline \multirow[b]{2}{*}{ Explaining } & \multicolumn{2}{|c|}{ Students } & \multicolumn{2}{|c|}{ Teachers } \\
\hline & Mean & $\begin{array}{c}\text { Verbal } \\
\text { Description }\end{array}$ & Mean & $\begin{array}{c}\text { Verbal } \\
\text { Description }\end{array}$ \\
\hline $\begin{array}{l}\text { 1. Expresses ideas which clear and } \\
\text { comprehensive }\end{array}$ & 3.84 & Very Good & 3.79 & Very Good \\
\hline $\begin{array}{l}\text { 2. Presents content that is relevant and covers } \\
\text { essential points }\end{array}$ & 3.42 & Very Good & 3.42 & Very Good \\
\hline 3. Possesses coordination in the statements. & 3.33 & Very Good & 3.37 & Very Good \\
\hline $\begin{array}{l}\text { 4. Uses fluent language so that the listeners and } \\
\text { readers listen and understand his/ her } \\
\text { thoughts. }\end{array}$ & 3.84 & Very Good & 3.84 & Very Good \\
\hline $\begin{array}{l}\text { 5. Is effective in the use of words, idioms or } \\
\text { connecting links }\end{array}$ & 3.16 & Good & 3.26 & Very Good \\
\hline 6. Has clear and effective beginning statement & 4.00 & Very Good & 3.95 & Very Good \\
\hline $\begin{array}{l}\text { 7. Uses proper words for explaining an object or } \\
\text { an event }\end{array}$ & 3.42 & Very Good & 3.47 & Very Good \\
\hline $\begin{array}{l}\text { 8. Words are simple, clear, concise and } \\
\text { interesting statements }\end{array}$ & 3.58 & Very Good & 3.63 & Very Good \\
\hline $\begin{array}{l}\text { 9. Exerts effort that make the listeners / readers } \\
\text { understand }\end{array}$ & 3.42 & Very Good & 3.42 & Very Good \\
\hline Average & 3.56 & Very Good & 3.57 & Very Good \\
\hline
\end{tabular}

Legend:

$\begin{array}{lll}3.25-4.00 & - & \text { Very Good } \\ 2.50-3.25 & - & \text { Good } \\ 1.75-2.50 & - & \text { Fair } \\ 1.00-1.75 & - & \text { Poor }\end{array}$

It can be gleaned on the Table that there was 3.56 average level of competence of the students. Expressing ideas which clear and comprehensive has a mean of 3.84 or very good; presenting content that is relevant and covers essential points has a mean of 3.42 or very good, possessing coordination in the statements has a mean of 3.33 or very good, using fluent language so that the listeners and readers listen and understand his/ her thoughts has a mean of 3.84 or very good, they are effective in the use of words, idioms or connecting links has a mean of 3.16 or good, having clear and effective beginning statement has a mean of 4.0 
or very good, using proper words for explaining an object or an event has a mean of 3.42 or very good, words are simple, clear, concise and interesting statements has a mean of 3.58 or very good, and exerting effort that make the listeners / readers understand has a mean of 3.42 or very good.

Level of competence on explaining of the students as perceived by the teacher respondents have 3.57 average mean that expressing ideas which clear and comprehensive has a mean of 3.79 or very good, presenting content that is relevant and covers essential points has a mean of 3.42 or very good, possessing coordination in the statements has a mean of 3.37 or very good, using fluent language so that the listeners and readers listen and understand his/ her thoughts has a mean of 3.84 or very good, they are effective in the use of words, idioms or connecting links has a mean of 3.26 or very good, having clear and effective beginning statement has a mean of 3.95 or very good, using proper words for explaining an object or an event has a mean of 3.47 or very good, words are simple, clear, concise and interesting statements has a mean of 3.63 or very good, and exerting effort that makes the listeners / readers understand has a mean of 3.42 or very good.

Table 2 presents the level of competence in the communication process of students as perceived by themselves and their teacher respondents in terms of interpreting.

Table 2. Interpreting

\begin{tabular}{|c|c|c|c|c|}
\hline \multirow{2}{*}{ Interpreting } & \multicolumn{2}{|c|}{ Students } & \multicolumn{2}{|c|}{ Teachers } \\
\hline & Mean & VD & Mean & VD \\
\hline $\begin{array}{l}\text { 1. paraphrases understanding of the meaning using the tools of } \\
\text { the target language }\end{array}$ & 3.00 & G & 3.00 & G \\
\hline 2. explains a thought to someone that are vague or broad & 3.26 & VG & 3.16 & G \\
\hline $\begin{array}{l}\text { 3. translates scientific concepts and terms into lay man's } \\
\text { language }\end{array}$ & 3.26 & VG & 3.11 & G \\
\hline 4. interprets broad and difficult and statements & 3.26 & VG & 3.16 & G \\
\hline $\begin{array}{l}\text { 5. Has thorough knowledge of the general subject to be } \\
\text { interpreted }\end{array}$ & 3.17 & G & 3.11 & G \\
\hline 6. Possesses intimate familiarity with cultures and disciplines & 3.26 & VG & 3.16 & $\mathrm{G}$ \\
\hline 7. Has extensive vocabulary in the required language & 3.26 & VG & 3.16 & G \\
\hline $\begin{array}{l}\text { 8. Can express thoughts clearly and concisely in the required } \\
\text { language }\end{array}$ & 3.26 & VG & 3.16 & $\mathrm{G}$ \\
\hline $\begin{array}{l}\text { 9. Uses simpler words instead of the technical and uncommon } \\
\text { words }\end{array}$ & 3.17 & G & 3.11 & $\mathrm{G}$ \\
\hline Average & 3.21 & G & 3.12 & G \\
\hline
\end{tabular}

Legend:

$\begin{array}{lll}3.25-4.00 & - & \text { Very Good } \\ 2.50-3.25 & - & \text { Good } \\ 1.75-2.50 & - & \text { Fair } \\ 1.00-1.75 & - & \text { Poor }\end{array}$

It can be gleaned on the Table that there were 3.21 or a good average mean level of competence of the students. Paraphrasing and understanding of the meaning using the tools of the target language has a mean of 3.0 or good, explaining a thought to someone that is vague or broad has a mean of 3.26 or very good, translating scientific concepts and terms into lay man's language has a mean of 3.26 or very good, interpreting broad and difficult and statements have a mean of 3.26 or very good, Having a thorough knowledge of the general subject to be interpreted as a mean of 3.17 or good, possessing intimate familiarity with cultures and disciplines has a mean of 3.26 or very good, having extensive vocabulary in the required language has a mean of 3.26 or very good, having the ability to express thoughts clearly and concisely in the required language has a mean of 3.26 or very good, and using simpler words in lieu of the technical and uncommon words has a mean of 3.17 or good.

The students' level of competence, as perceived by the teacher respondents, has a 3.12 or good average mean. Paraphrasing understanding of the meaning using the tools of the target language has a mean of 3.0 or good, explaining a thought to someone which are vague or broad has a mean of 3.16 or good, translating scientific concepts and terms into lay man's language has a mean of 3.11 or good, interpreting broad and difficult and statements have a mean of 3.16 or good, Having thorough knowledge of the general subject to be interpreted as a mean of 3.11 or good, possessing intimate familiarity with cultures and disciplines has a mean of 3.16 or good, having extensive vocabulary in the required language has a mean of 3.16 or 
good, having the ability to express thoughts clearly and concisely in the required language has a mean of 3.16 or good, and using simpler words in lieu of the technical and uncommon words has a mean of $3.11 \mathrm{or}$ good.

Table 3 presents the level of competence of the student and teacher respondents in a communication process in terms of applying.

Table 3. Applying

\begin{tabular}{|ll|c|c|c|c|}
\hline \multirow{2}{*}{ Applying } & \multicolumn{2}{c|}{ Students } & \multicolumn{2}{c|}{ Teachers } \\
\cline { 3 - 6 } & $\begin{array}{c}\text { Mea } \\
n\end{array}$ & $\begin{array}{c}\text { Verbal } \\
\text { Description }\end{array}$ & Mean & $\begin{array}{c}\text { Verbal } \\
\text { Descriptio } \\
n\end{array}$ \\
\hline 1. & Uses relevant theories and principles to emphasize ideas & 3.26 & Very Good & 3.16 & Good \\
\hline 2. & Applies the grammar rules in written language & 3.00 & Good & 3.00 & Good \\
\hline 3. & $\begin{array}{l}\text { Constructs sentences that are structurally and } \\
\text { grammatically correct }\end{array}$ & 2.92 & Good & 2.95 & Good \\
\hline 4. & Demonstrates expertise in oral language & 3.00 & Good & 3.00 & Good \\
\hline 5. & $\begin{array}{l}\text { Modifies complicated statements into short and simple } \\
\text { sentences }\end{array}$ & 2.83 & Good & 2.89 & Good \\
\hline $\begin{array}{l}\text { 6. } \\
\text { Relates statements that are relevant to the listener/ } \\
\text { reader }\end{array}$ & 3.00 & Good & 3.00 & Good \\
\hline 7. & Shows comparisons and differences to make a point & 2.84 & Good & 2.84 & Good \\
\hline 8. & Uses examples which are clear to the listeners/ readers & 2.57 & Good & 2.79 & Good \\
\hline 9. & $\begin{array}{l}\text { Applies what was learned in the classroom into novel } \\
\text { situations }\end{array}$ & 3.08 & Good & 3.00 & Good \\
\hline \multicolumn{2}{|c|}{ Average } & $\mathbf{2 . 9 4}$ & Good & $\mathbf{2 . 9 6}$ & Good \\
\hline
\end{tabular}

It can be gleaned on the Table that the weighted mean 2.94 is equivalent to the average level of competence of the students in applying skills. Using relevant theories and principles to emphasize ideas has a mean of 3.26 or very good, applying the grammar rules in written language has a mean of 3.0 or good, constructing sentences that are structurally and grammatically correct has a mean of 2.92 or good, demonstrating expertise in oral language has a mean of 3.0 or good, modifying complicated statements into short and simple sentences has a mean of 2.83 or good, relating statements that are relevant to the listener/ reader has a mean of 3.0 or good, showing comparisons and differences to make a point has a mean of 2.84 or good, using examples that are cleared to the listeners/ readers has a mean of 2.57 or good and applying what was learned in the classroom into novel situations.

The students level of competence of the students on applying as perceived by the teacher respondents has 2.96 or good average mean. Using relevant theories and principles to emphasize ideas has a mean of 3.16 or good, applying the grammar rules in written language has a mean of 3.0 or good, constructing sentences that are structurally and grammatically correct has a mean of 2.95 or good, demonstrating expertise in oral language has a mean of 3.0 or good, modifying complicated statements into short and simple sentences has a mean of 2.89 or good, relating statements that are relevant to the listener/ reader has a mean of 3.0 or good, showing comparisons and differences to make a point has a mean of 2.84 or good, using examples that are clear to the listeners/ readers has a mean of 2.79 or good and applying what was learned in the classroom into novel situations.

\section{Level of Adequacy of Instruction Materials in the Implementation of Communication Process}

Table 4 presents the level of adequacy of instructional materials in the implementation of the communication process.

Table 4. Adequacy of Instructional Materials

\begin{tabular}{|l|c|c|}
\hline \multicolumn{1}{|c|}{ Instructional Materials } & Mean & Verbal Description \\
\hline mock ups & 3.00 & Very Adequate \\
\hline Handouts & 3.00 & Very Adequate \\
\hline Catalogs & 3.00 & Very Adequate \\
\hline Syllabus & 2.81 & Very Adequate \\
\hline teacher's guide & 2.81 & Very Adequate \\
\hline computer with the internet & 2.81 & Very Adequate \\
\hline
\end{tabular}




\begin{tabular}{|l|c|c|}
\hline Dictionaries & 2.81 & Very Adequate \\
\hline Magazines & 2.80 & Very Adequate \\
\hline leaflets and pamphlets & 2.62 & Very Adequate \\
\hline Television & 2.61 & Very Adequate \\
\hline Manual & 2.60 & Very Adequate \\
\hline periodicals and clippings & 2.58 & Very Adequate \\
\hline DVDs & 2.44 & Very Adequate \\
\hline reference books, novels & 2.41 & Very Adequate \\
\hline Storybooks Average & 2.41 & Very Adequate \\
\hline Modules projector & 2.39 & Very Adequate \\
\hline LCD profin Adequate \\
\hline bulletins and circulars & 2.38 & Very \\
\hline \multicolumn{2}{|c|}{ Avequate } \\
\hline
\end{tabular}

Based on the Table, there was an average mean of 2.65 or very adequate. On the utilizations of instructional materials, mock ups have a mean of 3.0 or very adequate, handouts have a mean of 3.0 or very adequate, catalogues has a mean of 3.0 or very adequate, syllabus has a mean of 2.81 or very adequate, teacher's guide has a mean of 2.81 or very adequate, computer with the internet has a mean of 2.81 or very adequate, dictionaries have a mean of 2.81 or very adequate, magazines have a mean of 2.80 or very adequate, leaflets and pamphlets have a mean of 2.62 or very adequate, television has a mean of 2.61 or very adequate, manual has a mean of 2.60 or very adequate, periodicals and clippings has a mean of 2.58 or very adequate, DVDs has a mean of 2.44 or very adequate, reference books and novels has a mean of 2.41 or very adequate, storybooks have a mean of 2.41 or very adequate, modules have a mean of 2.39 or very adequate, LCD projector has a mean of 2.38 or very adequate, and bulletins and circulars have a mean of 2.23 or adequate.

Mandaue City College has enough instructional materials for teaching language subjects. Teachers are also utilizing the same to optimize the potentials and learning capabilities of the education students.

\section{Utilization of Methods and Techniques}

Table 5 presents the utilization of the communication process in terms of methods.

Table 5 Level of Utilization in terms of Methods

\begin{tabular}{|l|c|c|}
\hline \multicolumn{1}{|c|}{ Methods } & Mean & Verbal Description \\
\hline Reporting Method & 3.00 & Highly Utilized \\
\hline Others (specify) & 3.00 & Highly Utilized \\
\hline Deductive Method & 2.90 & Highly Utilized \\
\hline Demonstrative Method & 2.90 & Highly Utilized \\
\hline Inductive Method & 2.89 & Highly Utilized \\
\hline Lecture Method & 2.65 & Highly Utilized \\
\hline Integrative Method & 2.56 & Highly Utilized \\
\hline Activity Method Average & 2.44 & Highly Utilized \\
\hline \multicolumn{1}{|c|}{$\quad 2.79$} & Highly Utilized \\
\hline
\end{tabular}

Legend:
2.33-3.00-
(VA) Highly Utilized
$1.67-2.33-$
(A) Utilized
$1.00-1.67-$
(LA) Less Utilized

It can be gleaned in Table 15 that there was an average mean of 2.79 which was interpreted as highly utilized. On methods used by the teachers, reporting method has a mean of 3.0 or highly utilized, others (specify) has a mean of 3.0 or highly utilized, a deductive method has a mean of 2.90 or highly utilized, demonstrative method has a mean of 2.90 or highly utilized, inductive method has a mean of 2.89 or highly utilized, lecture method has a mean of 2.65 or highly utilized, an integrative method has a mean of 2.56 or highly utilized, and activity method has a mean of 2.44 or highly utilized. 
The teachers highly utilize all the methods in the teaching communication process. This means that the teachers provided all the opportunities for the students to learn because the teachers explored all the possibilities for teaching and learning.

Table 6 presents the level of utilization of the communication process based on techniques among the teachers in Mandaue City College.

Table 6 Level of Utilization in terms of Techniques

\begin{tabular}{|l|c|c|}
\hline \multicolumn{1}{|c|}{ Techniques } & Mean & Verbal Description \\
\hline Small Group Discussion & 3.00 & Highly Utilized \\
\hline Project & 3.00 & Highly Utilized \\
\hline Brainstorming & 3.00 & Highly Utilized \\
\hline Role Playing & 3.00 & Highly Utilized \\
\hline Modular Learning & 3.00 & Highly Utilized \\
\hline Interview & 2.90 & Highly Utilized \\
\hline Teacher - Directed & 2.90 & Highly Utilized \\
\hline Student - Directed & 2.90 & Highly Utilized \\
\hline Teacher - Student & 2.90 & Highly Utilized \\
\hline Demonstration/Lecture & 2.90 & Highly Utilized \\
\hline Mastery Learning & 2.90 & Highly Utilized \\
\hline Component Technique & 2.84 & Highly Utilized \\
\hline Dramatization & 2.84 & Highly Utilized \\
\hline Program Instruction & 2.84 & Highly Utilized \\
\hline Directed Learning & 2.80 & Highly Utilized \\
\hline Socialized Classroom Discussion & 2.73 & Highly Utilized \\
\hline Simulation/ Game & 2.73 & Highly Utilized \\
\hline Self Learning Kit and Correspondence & 2.73 & Highly Utilized \\
\hline Textbook Learning & 2.69 & Highly Utilized \\
\hline Unit or Morrison Technique & 2.63 & Highly Utilized \\
\hline Symposium & 2.63 & Highly Utilized \\
\hline Film Showing/Discussion & 2.63 & Highly Utilized \\
\hline Direct Discussion & 2.60 & Highly Utilized \\
\hline Lecture-Discussion & 2.60 & Highly Utilized \\
\hline Courses & 2.60 & Highly Utilized \\
\hline Others (specify) & 2.57 & Highly Utilized \\
\hline Field Trip & 2.56 & Highly Utilized \\
\hline Outlining Technique & 2.50 & Highly Utilized \\
\hline Individual or Group & 2.50 & Highly Utilized \\
\hline Debate Teaching & 2.50 & Highly Utilized \\
\hline Reporting Discussion & 2.50 & Highly Utilized \\
\hline Field Study & 2.50 & Highly Utilized \\
\hline Memorization & 2.47 & Highly Utilized \\
\hline Rule Technique & 2.46 & Highly Utilized \\
\hline Resources - Speaker & 2.44 & Highly Utilized \\
\hline Schematic & 2.36 & Highly Utilized \\
\hline Research & 2.36 & Highly Utilized \\
\hline Reading or Storytelling & 2.22 & Utilized \\
\hline Inductive/Deductive & & Highli Utilized \\
\hline & \\
\hline
\end{tabular}

It can be gleaned in table 15 that there was an average mean of 2.68 or highly utilized. On the techniques used by the teachers, small group discussion has a mean of 3.0 or highly utilized, project has a mean of 3.0 or highly utilized, brainstorming has a mean of 3.0 or highly utilized, role playing has a mean of 3.0 or highly utilized, modular learning has a mean of 3.0 or highly utilized, interview has a mean of 2.90 or highly utilized, teacher-directed has a mean of 2.90 or highly utilized, student-directed has a mean of 2.90 or highly utilized, teacher- student has a mean of 2.90 or highly utilized, demonstration/ lecture has a mean 
of 2.90 or highly utilized, mastery learning has a mean of 2.90 or highly utilized, component technique has a mean of 2.84 or highly utilized, dramatization has a mean of 2.84 or highly utilized, program instruction has a mean of 2.84 or very adequate, directed learning has a mean of 2.80 or highly utilized, socialized classroom discussion has a mean of 2.73 or highly utilized, simulation/ game has a mean of 2.73 or highly utilized, textbook learning has a mean of 2.69 or highly utilized, unit or Morrison technique has a mean of 2.63 or highly utilized, symposium has a mean of 2.63 or very adequate, film showing/ discussion has a mean of 2.60 or highly utilized, lecture-discussion has a mean of 2.60 or highly utilized, courses has a mean of 2.60 or highly utilized, others has a mean of 2.57 or highly utilized, field trip has a mean of 2.56 or highly utilized, outlining technique has a mean of 2.50 or highly utilized, individual or group has a mean of 2.50 or highly utilized, debate teaching has a mean of 2.50 or highly utilized, reporting discussion has a mean of 2.50 or highly utilized, field study has a mean of 2.50 or highly utilized, memorization has a mean of 2.47 or very adequate, rule technique has a mean of 2.46 or highly utilized, resources- speaker has a mean of 2.44 or highly utilized, schematic has a mean of 2.36 or highly utilized, reading or storytelling has a mean of 2.22 or utilized, and inductive or deductive has a mean of 2.22 or utilized.

Most of the techniques in the teaching communication process are highly utilized by the teachers at Mandaue City College. The two techniques which are on the level of utilized are reading/ storytelling and inductive/ deductive.

\section{Conclusion}

In relation to the level of competence of the student and teacher respondents in the communication process, it is exemplified that the college students are better at explaining compared to interpreting and applying. Moreover, the teachers utilize varied teaching methods and techniques for the students in tertiary education.

\subsection{Recommendations}

Based on the findings and conclusion, the following are the recommendations:

1. The proposals of this study are presented to the administration of Mandaue City College for implementation and application in actual classroom practice.

2. The college students' interpreting skills be strengthened through the teacher's employment of varied and engaging strategies to develop their ability to interpret critically.

3. Teachers should employ exercises that would develop their students' applying skills through written and oral exercises.

\section{References}

[1] Al Jabri, B. A. (2008). Vocabulary Teaching Techniques in an Omani Government School (Doctoral dissertation).

[2] Bovee, C.L., \& Thill, J.V. (2002). Business Communication Today. NY, NY: McGraw-Hill.

[3] Burnett, M.J., \& Dollar, A. (2009). Business Communication: Strategies for Success. Houston, Texas: Dane.

[4] Christie, James F. et.al. (2007). Teaching Language and Literacy: Preschool through the Elementary Grades. Third Edition. United States of America: Pearson Education Inc.

[5] Krystle, Sondra C., Chris Hadley, et al. ( 2012). How to Teach Literature to College.

[6] Ma, Jing ( 2013) A Study of Interpreting Skills from the Perspective of Interpreting Process . Journal of Language Teaching and Research, 4(6), 1232-1237, November 2013. Foreign Language Department, Qingdao University of Science and Technology, Qingdao China.

[7]Mwalyego, M. S. (2014). An investigation on the utilization of instructional materials in pre-primary schools in Morogoro municipal council (Doctoral dissertation, The Open University of Tanzania).

[8] Villalta-Cerdas, A. (2014). Development and Assessment of Self-explaining Skills in College Chemistry Instruction .University of South Florida [9] Villaroel, N. (2011). Young students' attitudes toward languages Claudia Navarro-villarroel lowa State University Graduate Theses and Dissertations Graduate College. 